\title{
Comunicação
}

(Communication)

\section{Contagem de células somáticas e isolamento de agentes causadores de mastite em búfalas (Bubalus bubalis)}

[Somatic cell count and mastitis causing pathogens isolation in water buffaloes (Bubalus bubalis)]

\author{
L.B. Carvalho ${ }^{1}$, F.R. Amaral ${ }^{2}$, M.A.V.P. Brito ${ }^{3}$, C.C. Lange $^{3}$ \\ J.R.F. Brito ${ }^{3}$, R.C. Leite ${ }^{4 *}$ \\ ${ }^{1}$ Aluno de pós-graduação - EV-UFMG \\ ${ }^{2}$ Médico Veterinário autônomo \\ ${ }^{3}$ Embrapa Gado de Leite - Juiz de Fora, MG \\ ${ }^{4}$ Escola de Veterinária - UFMG \\ Caixa Postal 567 \\ 30123-970 - Belo Horizonte, MG
}

Os bubalinos apresentam problemas sanitários semelhantes aos bovinos, como a mastite. As perdas com a mastite não estão ligadas somente ao produtor, uma vez que ocorrem além da redução em quantidade, mudanças na composição do leite. Para as indústrias de laticínios, isto significa problemas no processamento, redução do rendimento industrial e produtos lácteos com baixa qualidade e estabilidade. Por falta de informações sobre a espécie bubalina, utilizam-se para o controle da mastite as mesmas técnicas de criação e manejo indicadas para os bovinos.

O objetivo deste trabalho foi o de determinar a relação entre a contagem de células somáticas (CCS) do leite em presença ou ausência de isolamento microbiano em búfalas com ou sem ocorrência de mastite, avaliada pelo isolamento de microrganismos patogênicos em amostras de leite.

O trabalho foi realizado em oito rebanhos bubalinos leiteiros, escolhidos ao acaso, localizados na Região do Alto São Francisco, MG, distribuídos nos municípios de Luz, Dores do Indaiá, Estrela do Indaiá e Córrego D'Antas. $\mathrm{O}$ modo de produção era tradicional, de criação extensiva, com açudes para que os animais imergissem. A ordenha era manual, com bezerro

Recebido em 6 de julho de 2005

Aceito em 11 de dezembro de 2006

*Autor para correspondência (corresponding author)

E-mail: romulo@vet.ufmg.br ao pé, sem qualquer prática de higiene antes, durante e após a ordenha. Os rebanhos possuíam animais das raças Murrah, Mediterrâneo, Jafarabadi e seus mestiços. O período de observação foi de 270 dias, compreendendo março a novembro de 2003. Foram coletadas amostras compostas de leite para exames microbiológicos e CCS, separadamente, perfazendo um total de 1.393 amostras de leite (para cada exame) de todos os quartos mamários de 295 búfalas durante uma lactação (270 dias).

Para a avaliação da CCS, as amostras obtidas foram acondicionadas em frascos apropriados contendo o conservante Bronopol $\AA$, sendo imediatamente refrigeradas. A contagem de células somáticas foi realizada por meio de equipamento eletrônico SomaCount 300, pelo método de citometria de fluxo (Milk..., 1995). As amostras de leite para as análises microbiológicas foram obtidas e processadas de acordo com Harmon et al. (1990).

As bactérias do gênero Staphylococcus foram classificadas em coagulase-negativas, Staphylococcus aureus e Staphylococcus spp. coagulase-positivos de acordo com a produção de catalase, características das colônias em ágarsangue, morfologia e coloração de Gram, coagulação do plasma de coelho, produção de acetoína (Harmon et al., 1990) e presença ou ausência do gene femA (Mehrotra et al., 2000). 
Os gêneros Streptococcus, Enterococcus e outros cocos Gram-positivos catalase-negativos foram identificados de acordo com Facklam e Teixeira (1998). Os testes realizados incluíram ausência de produção de catalase, teste de Christie, Atkins e Munch-Peterson (CAMP), hidrólise da esculina e do hipurato de sódio, crescimento em meio contendo $6,5 \%$ de $\mathrm{NaCl}$, crescimento em presença de bile e esculina, tipo de hemólise em ágar-sangue contendo $5 \%$ de sangue desfibrinado de carneiro, tolerância ao telurito, produção de acetoína, sensibilidade à vancomicina, motilidade, crescimento a $10^{\circ} \mathrm{C}$ e $45^{\circ} \mathrm{C}$, produção da enzima pirrolidonil arilamidase (PYR), formação de ácidos a partir dos carboidratos (ribose, sorbitol, arabinose, lactose, trealose, inulina, rafinose e manose) e classificação sorológica baseada em antígenos de polissacarídeos de superfície.

Os bastonetes Gram-positivos foram classificados nos gêneros Corynebacterium e Arcanobacterium. As bactérias apresentando crescimento de colônias pequenas, circulares, esbranquiçadas ou cremosas, com a superfície rugosa, medindo 1 a $2 \mathrm{~mm}$ de diâmetro, com ausência de hemólise no ágar-sangue e produção de catalase, foram classificadas como Corynebacterium sp. Os esfregaços dessas culturas pelo método de Gram evidenciaram bastonetes Gram-positivos pequenos, pleomórficos e não esporulados, com morfologia semelhante a difteróides. A identificação das bactérias do gênero Arcanobacterium foi realizada de acordo com Funke e Bernard (2003), baseando-se nas seguintes características: teste de CAMP positivo, produção de catalase, hemólise e urease, oxidação/fermentação, motilidade, utilização de glicose, maltose, sacarose, manitol e xilose.
Bactérias Gram-negativas foram classificadas como Enterobacter sp., segundo Harmon et al. (1990), por meio de testes da urease, citrato, motilidade, indol, oxidação e fermentação, vermelho de metila, Voges-Proskauer e crescimento em ágar MacConkey. Leveduras foram identificadas por microscopia, após coloração de Gram.

Para avaliar as relações entre CCS e os microrganismos isolados, esses foram agrupados em contagiosos ( $S$. aureus e $S$. agalactiae), ambientais (outros Streptococcus spp., Lactococcus spp., Enterococcus spp. e Enterobacter sp.), secundários (Corynebacterium spp., Arcanobacterium spp., Staphylococcus spp. coagulase-negativo, Staphylococcus spp. coagulase-positivo e levedura) e associações (Radostits et al., 2002). Neste estudo fez-se uso de análise estatística descritiva (Sampaio, 2002).

A média, o desvio-padrão e a mediana para os patógenos contagiosos, ambientais e secundários, para as culturas em associação e para as amostras sem isolamento microbiológico estão apresentados na Tab. 1. Das 1.393 amostras analisadas, 57 (4,1\%) estavam contaminadas, isto é, houve crescimento de três ou mais tipos diferentes de colônias.

Amostras obtidas de leite com médias de CCS variando de $12.840 / \mathrm{ml}$ a $149.680 / \mathrm{ml}$ apresentaram infecção por diversos patógenos da mastite. Os maiores valores de CCS foram encontrados na presença de infecção mista (associações) e na presença de patógenos classificados como ambientais.

Tabela 1. Médias, desvios-padrão e medianas da contagem de células somáticas (CCS) (x1.000/ml de leite) em relação aos grupos de patógenos isolados a partir de amostras de leite de búfalas da região do Alto São Francisco-MG, 2003

\begin{tabular}{lcccc}
\hline \multirow{2}{*}{ Patógeno } & $\mathrm{N}$ & \multicolumn{3}{c}{ CCS x 1.000 } \\
\cline { 3 - 5 } & & Média & Desvio-padrão & Mediana \\
\hline Ausência de crescimento & 1.113 & 12,84 & 63,80 & 1,00 \\
Contagiosos & 26 & 45,27 & 125,23 & 7,50 \\
Ambientais & 27 & 74,67 & 130,50 & 5,00 \\
Secundários & 129 & 26,78 & 113,00 & 1,00 \\
Em associação & 41 & 149,68 & 468,76 & 4,00 \\
\hline
\end{tabular}


É possível que toda e qualquer vaca com CCS maior ou igual a $250.000 / \mathrm{ml}$, independente da paridade ou do estágio no período de lactação, tenha mastite subclínica (Harmon et al., 1990). Em búfalas, Galiero e Morena (2000) consideraram a CCS no leite normal entre 50.000 e $100.000 / \mathrm{ml}$. Kapronezai (2004) relatou valores de mediana para CCS de $8.500 / \mathrm{ml}, 10.350 / \mathrm{ml}$, $9.600 / \mathrm{ml}$ quando foram isolados Staphylococcus spp., Streptococcus spp. e Corynebacterium spp., respectivamente. Pelo Califórnia Mastite Teste (CMT) esse autor observou que a freqüência de quartos negativos e com isolamento microbiológico foi maior do que a freqüência de quartos positivos e com isolamento de microrganismos, indicando que há elevada freqüência de portadores ou que o teste de CMT não é um bom teste de triagem para mastite em bubalinos. As baixas CCS encontradas no presente trabalho reforçam a indicação de que o CMT não é um bom teste para detecção de mastite subclínica em bubalinos.

Algumas particularidades relacionadas a características anatômicas do úbere e tetos, imunologia da glândula mamária e composição do leite de búfalas podem conferir maior resistência contra a mastite. Essas incluem maior concentração de pigmentos de melanina, canal do teto com epitélio estratificado queratinoso mais espesso que o observado na vaca, camada muscular do esfíncter ao redor do canal do teto mais espessa e organizada, com maior tônus, mais rica em vasos sangüíneos e fibras nervosas, diâmetro menor do lúmen do canal do teto (Uppal et al., 1994), tipo de células e grau de atividade celular intramamária (Della Libera et al., 2004), maior atividade da enzima lactoperoxidase e maior concentração de lactoferrina no leite (Kapronezai, 2004). Esses aspectos podem explicar o grande número de amostras analisadas com resultado negativo no exame microbiológico e devem ser consideradas na elaboração de testes diagnósticos e programas de controle dessa enfermidade.

O padrão de contagem de células somáticas para bubalinos é diferente do normalmente encontrado em bovinos. Os baixos valores de CCS não indicaram necessariamente a ausência de infecção intramamária. Os parâmetros de CCS utilizados para bovinos podem não ser adequados para monitoramento de mastite em rebanhos de bubalinos.

Palavras-chave: búfalo, contagem de células somáticas, mastite, microbiologia

\begin{abstract}
The research was accomplished in eight dairy water buffalo herds, randomically choosen in Região do Alto São Francisco, State of Minas Gerais, Brazil. Information was collected from March to November, 2003 during 270 days of observation. In order to determine the somatic cell count (SCC) in presence or absence of microbial isolation, 1,393 samples were collected from 285 lactating females and microbiological exams and SCC were done. Samples obtained from udders without evidence of clinical or subclinical inflammation showed infection for a great variety of microbial mastitis pathogens. The low SCC did not necessarily indicate the absence of intramammary infection, suggesting that SCC patterns used for bovine cannot be appropriate in order to control mastitis in buffalo herds.
\end{abstract}

Keywords: water buffalo, somatic cell count, mastitis, microbiology

\section{REFERÊNCIAS BIBLIOGRÁFICAS}

DELLA LIBERA, A.M.M.P.; ARAÚJO, W.P.; KITAMURA, S.S. et al. Citologia do leite de búfalas (Bubalus bubalis) hígidas criadas no Estado de São Paulo, Brasil. Cien. Rural, v.34, p.1087-1092, 2004.

FACKLAM, R.R.; TEIXEIRA, L.M. Enterococcus. In: COLLIER, L.; BALOWS, A.;
SUSSMAN, M. (Eds.). Topley and Wilson's microbiology and microbial infections. 9.ed. London: Edward Arnold, 1998. v.2, cap.29, p.669-682.

FUNKE, G.; BERNARD, K.A. Corynefarm gram-positive rods. In: MURRAY, P.R.; BARON, E.J.; JORGENSEN, J.H. et al. Manual of clinical microbiology. 8.ed. Washington, DC: 
American Society for Microbiology, 2003. p.472-501.

GALIERO, G.; MORENA, C. The meaning of the somatic cell count in buffalo milk. Bubalus bubalis, v.1, p.26-27, 2000.

HARMON, R.J.; EBERHART, R.J.; JASPER, D.E. et al. Microbiological procedures for the diagnosis of bovine udder infection. Arlington: National Mastitis Council, 1990. 34p.

KAPRONEZAI, J. Estudo de provas microbiológicas e celulares em amostras de leite provenientes de fêmeas bubalinas (Bubalus bubalis) no Estado de São Paulo. 2004. 82f. Dissertação (Mestrado em Medicina Veterinária) - Faculdade de Medicina Veterinária e Zootecnia, Universidade de São Paulo, São Paulo.

MEHROTRA, M.; WANG, G.; JOHNSON, W.M. Multiplex PCR for the Detection of Genes for Staphylococcus aureus Enterotoxins,
Exfoliative Toxins, Toxic Shock Syndrome Toxin, and Methicillin Resistance. J. Clin. Microbiol., v.38, p.1032-1041, 2000.

MILK: enumeration of somatic cells. Bulletin of International Dairy Federation, n.148A, 1995. $8 \mathrm{p}$.

RADOSTITS, O.M.; GAY, C.C.; BLOOD, D.C. et al. Mastite. In: Clínica veterinária: Um tratado de doenças dos bovinos, ovinos, suínos, caprinos e eqüinos. Rio de Janeiro: Guanabara Koogan, 2002. p. 541-629.

SAMPAIO, I.B.M. Estatística aplicada à experimentação animal. 2.ed. Belo Horizonte: Fundação de Estudo e Pesquisa em Medicina Veterinária e Zootecnia, 2002. 265p.

UPPAL, S.K.; SINGH, K.S.; ROY, D.C. et al. Natural defence mechanism against mastitis: a comparative histomorphology of buffalo and cow teat canal. Buffalo J., v.10, p.125-131, 1994. 